\title{
Simulation Programs in Disaster Medicine
}

\author{
Evangelia Michailidou* \\ Consultant Anesthesiologist, General Hospital Hippokratio of Thessaloniki, Greece
}

*Corresponding author: Evangelia Michailidou, Consultant Anesthesiologist-Intensivist, General Hospital Hippokratio of Thessaloniki, Merkouriou 20 Thessaloniki, Greece.

To Cite This Article: Evangelia Michailidou. Simulation Programs in Disaster Medicine. Am J Biomed Sci \& Res. 2019 - 4(4). AJBSR.MS.ID.000812. DOI: 10.34297/AJBSR.2019.04.000812

Received: July 03, 2019 | Published: August 08, 2019

Keywords: Leadership; Teamwork; Scenario Awareness; Non-Technical Skills; Standards; Task Performance Analysis; Resurgence; Medical Emergency Team, Beside Author; Journal Searches

\section{Introduction}

The Significance Soft Abilities in the services of disaster medicine Soft skills are characterized as the individual qualities that empower a person to communicate adequately and harmoniously with others in stuff conditions and are fundamental for effective execution in any relational setting. According to Abbas [1] these properties are much more pivotal in the medical services industry of disaster medicine and not only, where therapeutic experts and representatives more nearly collaborate with patients and different human groups, as a rule under to great degree troublesome and passionate conditions. Accordingly, people work in disaster medicine issues should completely screen work possibility to guarantee they have the delicate aptitudes required to convey an outstanding level of care and administration to patients, while additionally having the capacity to effectively team up with staff individuals to boost hierarchical viability [2,3]. In the aviation business, accident analyses, machine analysis, and cockpit voice recordings unconcealed that unsafe conditions were overtimes associated with failures in staff ' non-technical (cognitive and social) skills, instead of an absence of technical data, ability to execute commands and algorithms. The correlation between the skills of the team members, the possible initiatives they may be required to take and the performance (quality and safety results) are decisive for the outcome of the mission $[4,5]$.

\section{Methodology}

Problem statement: In the period of the most recent century, the quantity of catastrophes has astoundingly expanded, showing that future ages of doctors will be called upon to give mass-setback treatment to a significantly more noteworthy degree than previously. Various examinations point to the absence of satisfactory preparing in the medicinal administration of catastrophe reaction
- an insufficiency that has turned out to be drastically clear in the ongoing past. In each real crisis there are yet noteworthy quantities of help staff who do not have a portion of the basic aptitudes, as a result, numerous legislatures and logical foundations concur that fiasco solution instruction ought to be incorporated into the standard restorative educational programs. The significance of improving instruction and preparing in a debacle of global safety and health has broadly been seen by medical understudies underlining that will react to massive disasters. This will be requiring specialist medical intervention which will be depend on non-technical skills. In any case, ongoing examinations have been demonstrated that exclusive a little level of restorative schools worldwide have included training of soft skills in medicine of catastrophes in their studies program. Along these lines, preparing restorative understudies to acquire non-technical skills through simulation, for getting to be helpful wellbeing experts is fundamental.

It adopted the following procedure for the Systematic methodology review:

a. Determining the research question and the appropriate studies

b. Search for studies

c. Selection of studies that meet the import criteria

d. Evaluation of the quality of the selected studies

e. Export data from studies

f. Statistical analysis of data (meta-analysis)

Subsequently for the selection of appropriate studies: All search results from various sources and removal of Duplicates with help from bibliographic reporting programs as PRISMA were merged 
the titles and abstracts of all reports and isolation of potentially relevant studies were rode. The full text of the potentially appropriate one's studies had been read (Table 1).

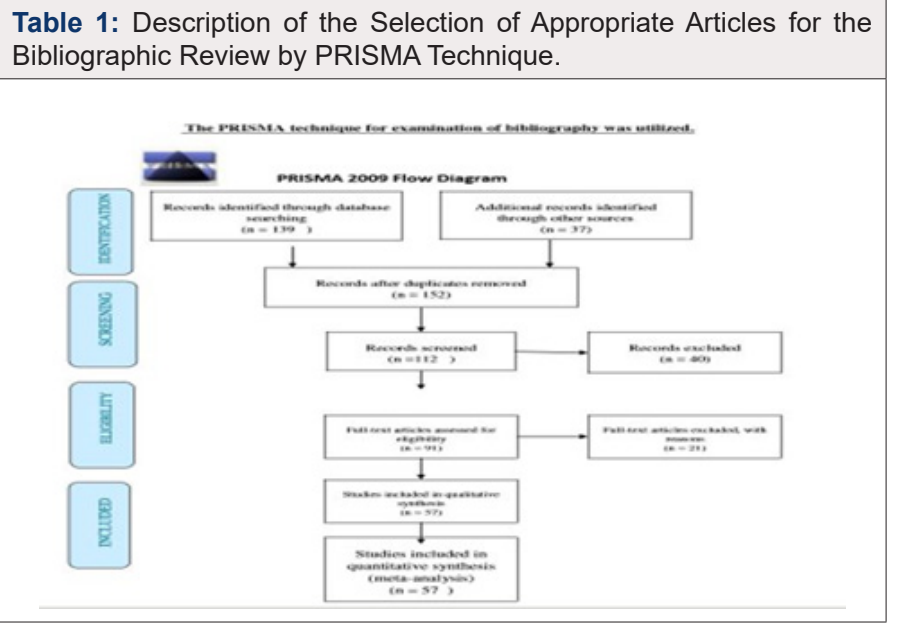

\section{Consideration/Prohibition Criteria}

Papers were incorporated that announced investigations:

a. Focusing on no specialized abilities estimates pertinent to the crisis mind condition.

b. That were embraced in any nation.

Papers were barred if they were:

a. Not accessible in English.

b. Did exclude or give access to the estimation instrument.

c. Related to specialized or clinical aptitudes estimates alone.

Following this, essential pursuit articles not meeting any of the consideration criteria by title or dynamic were barred; outstanding modified. A search of the literature was conducted to find and review instruments to quantify nontechnical skills including cooperation, leadership, higher cognitive process and scenario awareness. Electronic databases were searched from 2010 to 2018 and below are some of the databases used: Directory of open access books http://www.doabooks.org/ PubMed http://www.ncbi.nlm.nih. gov/pubmed/ Google scholar http://scholar. google.com/ Scirus http://www.scirus.com/Google book search http://books.google. com/ The Librarians' Internet Index http://www.lii.org/ Internet Public Library (IPL) http: //www.ipl.org as well as in: - MEDLINEEMBASE- Cochrane Register of Controlled Trials (CENTRAL) SCOPUS, NATIONAL \& KAPODISTRIAN UNIVERSITY OF ATHENS: Libraries \& Information Services, WEB OF SCIENCE (WOS), NATIONAL ARCHIVE OF DOCTORAL DISTRIBUTIONS / ECB , OPENACCESS, OPENARCHIVES, JOURNAL OF MAGAZINES (EDETB), ZEFYROS, ARGO, DOAJ, Free Medical Journals \& Free Medical Books (via the Amedeo medical database), OCLCECO, U.S. NATIONAL LIBRARY OF MEDICINE (NLM) - Databases \& Electronic Resources
Additionally, to the current, systematic searches of the cooperation literature, one by one performed by the authors, were accessed for key papers between 2010 and 2018. Reference has been made to important global writing there are some gaps in the literature that make the research meaningful and original. It is clear the relationship of the explanation behind the examination with the continuous written work about the issue, the reason and the investigation questions are clear. The method grasped to answer ask about the request is appropriate.

a. Data aggregation instruments have been adequately delineated and endorsed and trustworthy.

b. Pleasing elucidations for the results are given.

c. The ends rely upon the data assembled.

d. The methodological obstructions of the investigation are seen.

e. The structure and relationship of the parts of the investigation is clear

f. Isolation of studies that meet the import criteria

Measurable examination of information was performed utilizing SPSS 16.0 programming (Chicago, IL, USA). The between rater unwavering quality was estimated utilizing an intra-class relationship. For all tests, a P-estimation of $<0.05$ was viewed as noteworthy (two-sided).

\section{Main Part}

The impersonation of a true procedure or task of a framework over time. Envelops the advancement of a model that will repeat the key highlights and characteristics of a real framework. The model speaks to the framework itself, while reproduction speaks to the conduct of the framework after some time Utilized with progress over the long haul in Flying Military Driving Transportation, Vehicles, Urban arranging Assembling Solution Medicinal recreation is a moderately new idea for preparing and assessment of doctors in disaster medicine incorporates a differing scope of procedures.

The main occurrence of medicinal reproduction was by Dr. Gregoire of Paris in the seventeenth century [6], utilizing a puppet he intended to show helped and muddled conveyances to birthing specialists. Reenactment has advanced throughout the years to extend from utilizing institutionalized patients to automated patients; from part-undertaking mentors to high-constancy puppets numerous fields in prescription are developing into an interventional and hands-on way to deal with handling medical problems. Recreation has been generally utilized in disaster medicine pieces of preparing Careful fields are additionally utilizing reenactments to pre-establish methods (Figure 1).

These weren't supposed to be specifically just like the living body, however rather a basic reproduction permitting midwives to 
grasp the position of the kid within the passageway [8]. By permission of the Dittrick Medical History Center and Museum. As of late received into disaster health crisis preparing over the world. Crisis prescription as a claim to fame involves acing both information and fitness.

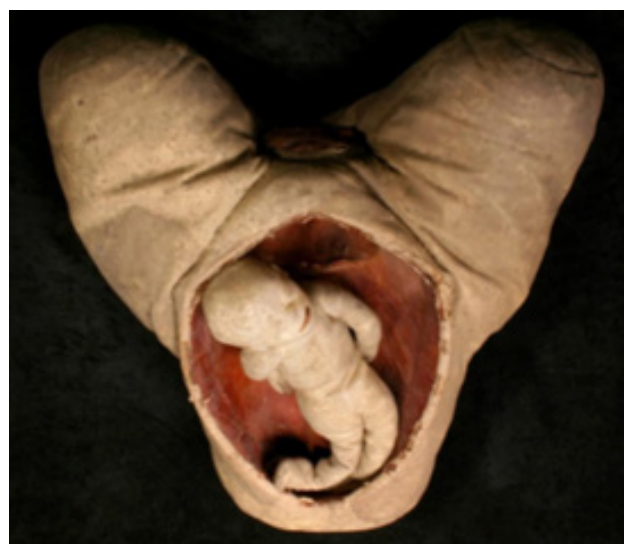

Figure 1: Late seventh-century "birthing phantom

\section{Characterization}

Virtual reenactment where genuine individuals utilize recreated gear in a reproduced world or virtual condition. Live reenactment where genuine individuals utilize recreated or sham hardware. Emergency asset administration (CRM) requires two arrangements of abilities: both specialized aptitudes Technical Skills (TS) and non-specialized abilities or better non-technical skills (NTS) or conduct execution. TS have been characterized as the 'ampleness of the moves made from a therapeutic and specialized point of view', and NTS have been characterized as 'basic leadership and group association forms utilized amid the group's administration of a circumstance'[1,7,13,16-38].

There is an absence of major understanding whether great technical skills execution is joined by great execution, or whether the preparation of nontechnical skills affects the execution of TS amid emergency [9]. Understanding the connection between these two traits in such circumstances could have expansive ramifications for clinical execution preparing, evaluation, and research. This investigation expects to decide the connection amongst technical skills and non-technical skills amid a reenacted emergency. We conjecture that TS and NTS are related and are not autonomous of each other amid emergency circumstances [10-12].

\section{Conventional and Contemporary Training}

As of late, medicinal college training has started to show an alternate way to deal with both the conventional model of living educating and clinical practice by managing okay and multifaceted nature under the supervision of an administering educator [13]. Lately, innovative and logical disclosures have started and are being utilized in medicinal instruction as much and in disaster medicine, going for the quick, fast, subjective, worldwide and self-coordinated routine with regards to restorative learning and aptitudes.
Additionally, the consistent stream of subjective, inquire about and down to earth data, which is currently created in a quick and regularly expanding way, has started to invite some inflexibility in the best possible method for learning and comprehension through conventional means [14]. Albeit these days a piece of the clinical preparing happens, all things considered, circumstances [generally okay and dependable with the nearness of a director], therapeutic preparing has turned out to be progressively delicate to security issues and the nature of arrangement of medicinal administrations in emergent situations. In this manner, better approaches for learning and honing are being looked for which can be connected in a controlled situation for instructing to manage uncontrolled breakdowns such as those in mass casualties [15-35]. So, it becomes perceived that this procedure will require the clinical treatment of instances of rich assorted variety [35] (Figure 2).

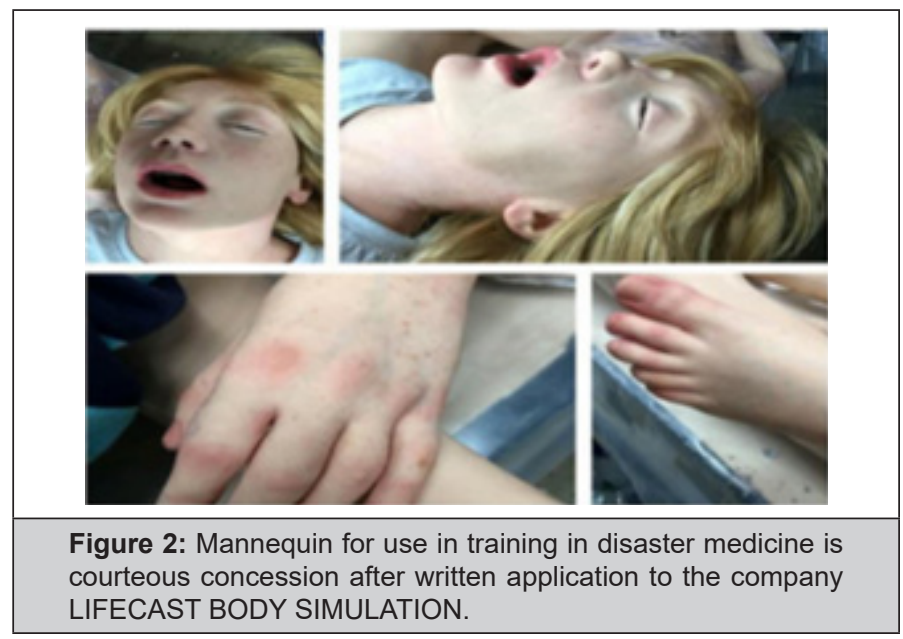

Simulation training utilizing reproduction advancements is a logical field, which goes for decreasing many the inconveniences related to the conventional learning model. Experimental simulation programs have sufficiently acquired proof from the effective utilization of pilot training programs for a long time in the field of aeronautics. Specifically, pilot test programs have loaned to their individual therapeutic highlights, for example, high photorealism amid a virtual flight, the deluge of multisensory information into the assessment and utilization of material criticism and complex movement advances. From a specialized perspective, this information is straightforwardly pertinent to restorative instruction, what's more rehearsing - realizing they can likewise be utilized to unabashedly assess, enhance and sort the trainee's specialized abilities. The term reproduction incorporates into expansion to its instructive measurement and its scientific - computational frame.

Specifically, medicinal models are frequently utilized in the restorative science to mimic different minuscule marvels (for example photon collaboration with MONTECARLO) $[21,33,49]$. Be that as it may, these models, which are for the most part of measurable starting point, are called upon to depict and dissect a wonder at a minute level with a specific end goal to make valuable determi- 
nations, for the structure/type of a tissue or an injury, the method of communication of the radiation [53]. Restorative recreation in instruction is an alternate space, going for the sensible reenactment of plainly visible wonders experienced in the clinical schedule, going for better training and assessment of learners. In any case, computational models, for example, MONTECARLO procedures can likewise be utilized in the instructive reenactment, however, to investigate and decipher the information created by the separate test systems $[21,33,49]$. In outline, one could state that computational reenactment can be an apparatus for instructive recreation in medical training in massive destruction, however not vice versa.

\section{Identity and conduct tests}

As a valuable proportion of group working potential and basic leadership, the most widely recognized identity test is the Myers Briggs Type Indicator (MBTI) which is controlled to more than 3.5 million individuals for every annum [42-45]. The measure depends on Jung's hypothesis of mental sorts which portrays an attention on the outside universe of individuals, things and experience (extroversion) and the interior universe of internal procedures and reflections (self-preoccupation). Of potential use to restorative group improvement is Catell's Personality Factors Test (16PF), which recognizes a gathering of practices that describe an identity compose, yet in addition incorporates a thinking capacity measure [19-43].

Estimating identity is enlightening, albeit restricted, in that identity winds up settled at an early age. More helpful maybe is a proportion of favored conduct which empowers both individual and group knowledge [33-36]. Key Interpersonal Relations Orientation - Behavior (FIRO-B) is one such instrument which estimates zones of relational needs (both communicated and needed) distinguished as consideration, control and warmth. Social inclinations can likewise be mapped as a group profile $[12,19,26]$. These apparatuses have potential in the crisis mind field depending the requirements of the ED. Some can be utilized as proportions of potential or of individual, initiative or group execution that might be appraised without anyone else, subordinates or companions, through review or direct evaluations of observational execution. While choosing an instrument it isn't just imperative to think about the legitimacy, dependability and plausibility of the measure however the foci required [4-23].

For instance, the Leadership Practices Inventory [13] consolidates classes, for example, 'demonstrating the way' and 'empowering the heart' which might be excessively wide an order for the private examination of crisis conduct, while Team Excellence and the Leader Behavior Description Questionnaire (LBDQ) [13-15] utilize a more engaged miniaturized scale way to deal with the estimation of group practices. The connection between NTS classifications and the TS agenda score had factually huge relationships, with running from 0.31 to 0.45 .

\section{Table-Top Simulation}

During this kind of simulation, the intellectual and communicative setting, however not the physical one is replicated. As a rule, table-top simulations permit a combination of face to face teaching with the addition of some sensible exercises which offer the learners with the likelihood of swing their gained information into restricted follow. Largely, these simulations are scenario-based $[1,19]$. During this type of teaching the degree of reality will be varied to elucidate period problems like lack of communication. Studies on the consequences of table prime simulation on student perception of disaster preparation and management has shown that compared to field operation exercises, this technique provides higher potentialities to link the results of exercises to acceptable changes in terms of coaching, equipment, supplies, and plans and conjointly provides extra advantages for communications, coordination, assignment of responsibilities, and post-event mitigation priorities. Rudolph [51] uses one example for such coaching model is MIMMS (Major Incidents Medical Management and Support). MIMMS has been and is employed as a coaching course in several countries and is a method of standardizing the key incident management.

However, it's primarily been healthcare-oriented and lacks the period ideas with relevance consumed time for various live like swing IV-line or stabilization of the cervical spine. it's correct for showing the scene organization Associate in Nursing to disaster medicine to an extent however the organization of the hospital will be designed up, however the probabilities of interactive coaching of alternative components of the chain of response to major incidents is restricted [47-53].

\section{Computer-Based Simulation}

During this kind of simulation there may well be no human interaction. However, the tactic will be improved if every or restricted range of scholars has their own pedagogue. During this technique accent material, simulation exercises and programmed learning are given to the scholar while not the presence of a tutor or trainer. Subtle e-learning programs may supply semi-AI responses (an intelligent response system), recommend routes to explore, and management the speed of learning betting on the student's input. In follow, the scholar solely needs a laptop of given power. A less technologically mediated system would come with internet-broadcast lectures, films, or demonstrations, and the provision of labor (e.g. written papers) to a personality's teacher (Figure 3).

The strength of the system is that each student has the chance to find out at her/his own pace and time. Sufficiently subtle programming will judge students, guide them, and supply all necessary materials. Course materials will simply be updated. There's no limitation in range of participants, as they use their own house and time to catch up with the teachings [48-53]. Learners have therefore time to rigorously replicate and supply proof for his or her feed- 
back. The weaknesses of the system are the large resources it wants and the long time it takes to develop initial course.

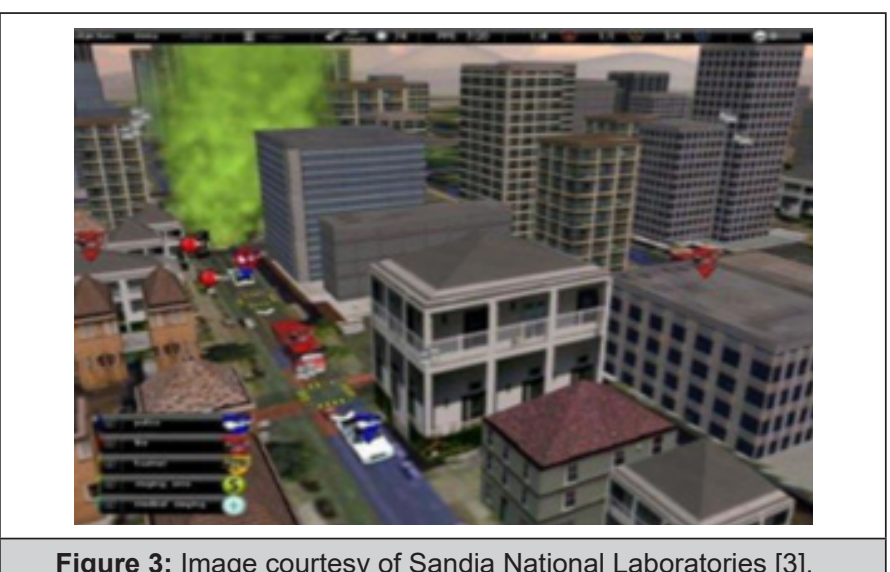

Figure 3: Image courtesy of Sandia National Laboratories [3]

Alternative points to contemplate are isolation and loneliness of scholars while not human contact with teacher, that results in less motivation and slower progression and lower learner satisfaction. There are several tries to form this sort of simulation accessible for coaching with restricted success. The general expertise so far indicates that operating with this sort of coaching doesn't fulfill the demand for interactive involvement of scholars [47-53].

\section{Real-Time Simulation}

During this kind of simulation over five hundredth of the course stress is on the crisis resource management and totally different aspects of the crisis like personnel, resource and time management are trained in specific things. The nucleus of the course is realistic simulations followed by careful debriefings. Simulation coaching will be supplemented by extra modalities like videotapes and role-playing to reinforce the supreme learning [47-53]. Simulation strives for prime degree of realism and so is conducted with workers and participants usually set at their normal operating setting. Situations have interaction participants in acceptable interactions and enhance cooperation, vertically in own organization and horizontally together with alternative organizations. These situations aim to ascertain inter-individual and inter-disciplinary interaction by asking and receiving helps. Workers could rotate among \{different totally different completely different\} stations to find out every positions potentialities and limitations to achieve different views [13-42].

Examination are crystal rectifier by one or a lot of instructors with special coaching or expertise and might be performed in whole cluster or separately to explore aspects of behavior and emphasize constructive critique and offers participants chance to find out from one another and to do and train to find out. Coaching is intense and possible, and the range of instructors will be adjusted to range of participants and also the structure of the course. According to Schon [52] this kind of coaching will be conducted by mistreatment figurants or patient cards.
Simulation coaching mistreatment figurants or "Field Exercises". This model is incredibly resource overwhelming and therefore expensive. It typically wants great deal of figurants to check all levels in an exceedingly disaster management system and disturb the continued and daily medical aid activities. b. Simulation coaching mistreatment patients 'card is one kind of simulation system which might be accustomed train and judge the total chain of response (Scene, transport, hospitals, command and communication) and coordination between totally different parts of the chain and the obtained results (outcomes). The coordination is by expertise one in all the foremost vital components of the response and its failure is often mentioned because the main reason for non-optimal outcome [40-53].

\section{Is Simulation the Best Choice in Training of Disaster Medicine [1-57]?}

Instructional plan ought to be founded on learning targets, student needs, wellbeing concerns, asset usage Virtual patients frequently used to educate clinical thinking Technology-improved reenactment is regularly for procedural preparing. How Do We Optimally Implement Simulation Education? More research to elucidate how to pick amongst sum and non-sum approaches Cost viability research to decide the genuine and correlation estimation of sum instruction. How Do We Optimally Implement Simulation Education? Near viability research should center on what works in reenactment - for which gathering of people-for what conditions-and at what cost. Assignment investigation should center on basic activities and can help decide the level of devotion important for the sort of preparing. How Do We Optimally Implement Simulation Education for training in disaster medicine? Watchful choice and sequencing of occasions encompassing the recreated errand Appropriate personnel improvement and bolster Institutional promise to reproduction [33].

Teamwork is central to the acquisition of non-technical skills (NTS), that are delineated as 'the psychological feature, social and private resource skills that complement technical skills, and contribute to safe and economical task performance, they're believed to be an important element of preparation for follow [42-53]. While simulation suites square measure currently commonplace, significantly in medium to high resource countries, several medical students receive restricted simulation experiences to develop their non-technical skills. Educators typically believe that the legitimacy and fidelity of simulation got to replicate the complexness of the ability being learned which hi-fi is critical for teaching advanced skills like cooperation, styles that square measure resource and time intensive aren't property for delivery to giant cohorts. Nevertheless, there's very little proof on the dimensions at that simulation is often productive [12-46]. At a similar time, it's familiar that interactive giant cluster teaching will manufacture smart learning outcomes. Studies comparison high and low fidelity simulations 
have shown stripped will increase in learning, if a 'baseline authenticity' is obtained [19].

Fidelity exists in 2 major planes; 'engineering' [physical] and psychological, the latter being a lot of powerful in reassuring effective learning, once essential crucial parts exist within the situation. Despite engineering triumphs reminiscent of computerized voices and harm wounds, simulations of lack 'sociological fidelity'. this manner of fidelity takes account of the mixing of an advanced vary of skills, attitudes and behaviors, that need a firm understanding on however factors reminiscent of imbalances of authority and influence, impact on collaborating and negotiating processes (these are advanced technical activities in their own right) [16-42]. An opportunity to analyze a number of these problems arose within the style and implementation of an outsized category learning and teaching activity, framed as a simulation of a natural disaster, so as for medical students to develop the non-technical skills essential to health care team operating [3-5]. We have incontestable the satisfactoriness and academic effectiveness of a large class teaching model for people trainees learning the non-technical skills of collaboration, negotiation and communication during a simulated disaster drugs context.

Our findings are of interest to medical faculties in disaster prone areas, as well as inside low resource countries, and as a possible intervention for learning the non-technical skills that square measure required for patient safety $[48,53]$.

\section{Conclusion}

A series of substantial and reliable non-specialized expertise measures are accessible as soft skills, but only two articles have been used in the real-world crisis and have developed the simulation as a non-technical skill training tool only. There is a requirement to extend the assessment of cooperative skills to enhance a more meaningful understanding of team performance and to enhance the well-being of crisis tolerance that will be developed through a simulation program alone. Many papers refer to non-technical skills training, but do not focus exclusively on it. Always include or compare technical skills. This review inter alia demonstrated that TS and NTS are related and are not free of each other amid disaster emergent medicine. The idea of this relationship still can't seem to be tended to. This examination gives the premise to future investigations assessing the impact of NTS preparing on the execution of TS, and whether NTS are non-specific and transferable between emergencies that require distinctive TS.

A large category teaching activity, framed as a simulation of a natural disaster is an appropriate and effective activity for medical students to develop the non-technical skills of collaboration, negotiation and communication, that area unit essential to team operating. The look may well be important in medical colleges in disaster prone areas, as well as among low resource countries, and as a possible intervention for learning the non-technical skills that area unit required for patient safety. Generally knowledge indicated the satisfactoriness and effectiveness of an outsized category simulation of natural disaster in demonstrating non-technical of skills of collaboration, negotiation and communication as learning outcomes There square measure variety of implications for medical and health educators want to develop massive scale disaster simulations to produce teaching and learning around team skills. Effectiveness analysis aims to spot academic interventions that may add a spread of settings. Specially understanding however refinements to the academic style is created, and prices managed thus health educators is also ready to adapt this model for fulfillment with their own students. While their square measure extremely protocoled emergency responses ready to be with success rehearsed by groups in sound reproduction simulation settings, most health care work isn't routine and sometimes chaotic. 'To act effectively in complicated things, team members have to be compelled to listen to all or any potential sources of knowledge and integrate that info into team action'.

These options and also the criteria mentioned within the methodology section of this study match the required coaching during a multidisciplinary atmosphere, within which students area unit deeply engaged in skills coaching by associate degree attempt\} to unravel issues in an atmosphere that's the same as those to be encountered in world [49-53]. One such coaching that has already gained interests in European countries is MRMI (Medical Response to Major Incidents), that relies on MacSim (Mass Casualty Simulation). It fulfills all criteria planned within the literature for a fascinating simulation training; it provides feedback by instructors, creates opportunities for repetitive observe, is integrated within the academic syllabus, presents a spread of problem levels, permits multiple learning methods, provides a spread of clinical eventualities, ensures a secure and educationally ancillary learning atmosphere, provides each team- and personalized learning, has outlined outcomes and is scientifically valid Instructions for future research on the subject Guidelines for future research on the subject Current careful practice requires; specialized and non-specialized skills, confirm the practice, emphasize deep-rooted commitment, control of results and a strong governance and education structure in the field of medical disaster.

Finally, these necessities must be combined with various individual and specialized qualities, including correctness, proven ability, and empathic, quiet focused care through simulation programs. Research is currently focused on the means by which the absence of non-specialized skills causes tolerant defamation, as the general reasoning is that it weakens the specialized execution. We found that input acceptance and sustainable adaptation to occasional unpleasant actions in the work environment had beneficial effects on specialized execution. On the other hand, large amounts of frustration of exhaustion and cooperation were clearly linked to the specific error. Being a dignified specialist is different from being a de- 
cent "hand combination" is tied to a decent cooperative person who co-ordinates and discusses well with patients and their associates and pledges them to achieve their maximum potential.

For guidance for effective transfer from aviation to alternative work arrangements such as health care and medicine of mass disasters, it must be strictly designed to address the non-technical skills required for specific this this area. It is not enough to require training materials and easily delete "pilot" and replace it with "nurse" or "anesthetist". Medicine, and more so, the unknown environment of urgency presents significant deviations in specialized and national cultures that exert powerful influences on acceptable behaviors, compared to pilots, since simulation programs were first used and created for them. It is completely wrong simply disaster medicine to replicate the simulation programs that created for pilots

Well-grounded development of behavioral markers to be used in disaster medicine have fashioned the premise for development of many courses by simulation addressing team skills, whereas NTS emphasizes the individual skills of a specific specialty inside a team, initial experiences that smart team performance goes on the far side the contributions of the people and additional work, particularly around team state of affairs awareness, and shared mental models in these difficult things is guaranteed. We conjecture that TS and NTS are related and are not autonomous of each other amid emergency circumstances.

\section{References}

1. A Abass O, O Samuel B, T Odufeko G (2014) Medical Simulation a Tool yet Untapped in Most Developing Nations in Africa. International Journal of Computer Applications 97(5): 1-4,

2. Grierson LE (2014) Information processing, specificity of practice, and the transfer of learning: considerations for reconsidering fidelity. Adv Health Sci Educ19(2): 281-289.

3. Lancman B, Jorm C (2015) Taking the heat in critical situations: being aware, assertive and heard. In: Iedema $\mathrm{R}$ et al. (Eds). Communicating quality and safety in health care. PRISMA statement (Preferred Reporkng Items for Systemakc reviews and Meta-Analyses). Cambridge University Press, Melbourne. pp. 268-278.

4. Gordon M, Darbyshire D, Baker P (2012) Non-technical skills training to enhance patient safety: a systematic review. Med Educ 46(11): 10421054.

5. Babafemi O Samuel, Gabriel T Odufeko, Olalere A Abass (2014) Medical Simulation a Tool yet Untapped in Most Developing Nations in Africa. International Journal of Computer Applications (0975-8887) 97(5).

6. Karamaggiolis Evika, Karydis Kostelia, Pikoulis Emmanouil (2017) Training in Emergency Medical Disaster Management, p. MSc Environmental Education at Agave University of Rhodes, Rhodes.

7. (2018) The Literature on Health Care Simulation Education: What Does It Show? AHRQ Patient Safety Network [Internet]. Psnet.ahrq.gov.

8. Cook DA (2011) Technology-Enhanced Simulation for Health Professions Education [Internet]. JAMA Internal Medicine. American Medical Association.

9. Zendejas B, Wang AT, Brydges R, Hamstra SJ, Cook DA (2013) Cost: The missing outcome in simulation-based medical education research: A systematic review. Surgery 153(2): 160-176.
10. Khorram Manesh A, Lönroth H, Rotter P, Andersson AN, Carlström E, et al. (2017) Non-medical aspects of civilian-military collaboration in management of major incidents. Eur J Trauma Emerg Surg 43(5): 595-603.

11. (2013) United Nations International Strategy for Disaster Reduction (UNISDR). Terminology on Disaster Risk Reduction.

12. http://crisis.med.uoa.gr/downloads/Odigos-Spoudwn-2014.pdf

13. Lampi M, Vikström T, Jonson CO (2013) Triage performance of Swedish physicians using the ATLS algorithm in a simulated mass casualty incident: a prospective cross-sectional survey. Scandinavian Journal of Trauma, Resuscitation and Emergency Medicine 21: 90.

14. Radestad M, Nilsson H, Castren M, Rüter A, Gryth D et al. (2012) Combining performance and outcome indicators can be used in a standardized way: a pilot study of two multidisciplinary, full-scale major aircraft exercises. Scand J Trauma Resusc Emerg Med 20: 58.

15. Khorram-Manesh A, Berlin J, Carlström E (2016) Two Validated Ways of Improving the Ability of Decision-Making in Emergencies; Results from a Literature Review. Bull Emerg Trauma 4(4): 186-196.

16. Gardner AK, DeMoya MA, Tinkoff GH, Brown KM, Garcia GD, et al. (2016) Using simulation for disaster preparedness. Surgery $160(3)$ : 565-570.

17. Walker WE, Giddings J, Armstrong S (2011) Training and learning for crisis management using a virtual simulation/gaming environment. Cogn Technol Work 13(3): 163-173.

18. Kleiboer M (1997) Simulation Methodology for Crisis Management Support. J Contingencies Crisis Manag 5(4): 198-206.

19. Lampi M, Vikström T, Jonson CO (2013) Triage performance of Swedish physicians using the ATLS algorithm in a simulated mass casualty incident: a prospective cross-sectional survey, Scandinavian Journal of Trauma, Resuscitation and Emergency Medicine 21: 90

20. Swathi JM, González PA, Delgado RC (2017) Disaster management and primary health care: implications for medical education. Unit for Research in Emergency and Disaster, Faculty of Medicine, University of Oviedo, Spain. Int J Med Educ 8: 414-415.

21. Hunter JC, Yang JA, Petrie M, Aragón TJ (2012) Integrating a framework for conducting public health systems research into statewide operations-based exercises to improve emergency preparedness BMC Public Health 12: 680 .

22. Weaver SJ, Dy SM, Rosen MA (2014) Team-training in healthcare: a narrative synthesis of the literature. BMJ Qual Saf 23(5): 359-372.

23. Salas E, Rosen MA (2013) Building high reliability teams: progress and some reflections on teamwork training. BMJ Qual Saf 22(5):369-373.

24. Bligh J, Bleakley A (2006) Distributing menus to hungry learners: can learning by simulation become simulation of learning? Med Teach 28(7): 606-613.

25. Flin R, O’Conner P, Crichton M (2008) Safety at the Sharp End: A guide to non-technical skills. Aldershot: Ashgate publishing.

26. Tallentire VR, Smith SE, Skinner J, Cameron HS (2011) The preparedness of UK graduates in acute care: a systematic literature review. Postgrad Med J 88(1041): 365-371.

27. McGaghie WC, Issenberg SB, Petrusa ER, Scalese RJ (2010) A critical review of simulation-based medical education research: 2003-2009. Med Educ 44(1): 50-63.

28. Hamstra SJ, Brydges R, Hatala R, Zendejas B, Cook DA (2014) Reconsidering fidelity in simulation-based training. Acad Med 89(3): 387-392.

29. Roberts C, Lawson M, Newble D, Self A, Chan P (2015) The introduction of large class problem-based learning into an undergraduate medical curriculum: an evaluation. Med Teach 27(6): 527-533.

30. Norman G, Dore K, Grierson L (2012) The minimal relationship between simulation fidelity and transfer of learning. Med Educ 46(7): 636-647. 
31. Lorello G, Cook D, Johnson R, Brydges R (2014) Simulation-based training in anesthesiology: a systematic review and meta-analysis. Br J Anaesth 112(2): 231-245.

32. Sandars J (2015) The use of reflection in medical education: AMEE Guide No. 44. Med Teach 31(8): 685-695.

33. Stark P, Roberts C, Newble D, Bax N (2016) Discovering professionalism through guided reflection. Med Teach 28(1): e25-e31.

34. Rudolph JW, Simon R, Dufresne RL, Raemer DB (2006) There's no such thing as "nonjudgmental" debriefing: a theory and method for debriefing with good judgment. Simul Health 1(1): 49-55.

35. Schon D (2013) The reflective practitioner: how professionals think in action. Basic Books, New York.

36. Schön D (2017) Educating the reflective practitioner: toward a new design for teaching and learning in the Professions. San Francisco: JosseyBass.

37. Reeves S, Peller J, Goldman J, Kitto S (2013) Ethnography in qualitative educational research: AMEE Guide No. 80. Med Teach 35(8): e1365-e1379.

38. Kunkler K (2016) The role of medical simulation: an overview. The International Journal of Medical Robotics and Computer Assisted Surgery. 2(3): 203-210

39. Nkechi Oluwakemi Dike (2018) - PPT video online download [Internet]

40. Odufeko G (2018) Medical Simulation a Tool yet Untapped in Most Developing Nations in Africa [Internet]. International Journal of Computer Applications-IJCA.

41. Murphy J, Cremonini F, Kane G, Dunn W (2018) Is simulation-based medicine training the future of clinical medicine? Mayoclinic.pure.elsevier.com.

42. McGaghie W, Issenberg S, Cohen E, Barsuk J, Wayne D (2011) Does Simulation Based Medical Education with Deliberate Practice Yield Better Results Than Traditional Clinical Education? A Meta-Analytic Comparative Review of the Evidence. Acad Med 86(6): 706-711.
43. Okuda Y, Bond W, Bonfante G, McLaughlin S, Spillane L, et al. (2008) National Growth in Simulation Training within Emergency Medicine Residency Programs, 2003-2008. Acad Emerg Med 15(11): 1113-1116.

44. Moore K, Kahn JA (2017) Public Health Emergency Simulation Tool for Enhanced Training in Emergency Preparedness and Response. Prehospital and Disaster Medicine 32(S1): S203.

45. Rosen KR, Mcbride JM, Drake RL (2009) The use of simulation in medical education to enhance students understanding of basic sciences. Medical Teacher 31(9): 842-846.

46. Cook DA, Brydges R, Hamstra SJ, Erwin PJ, Hatala R, et al. (2012) Comparative effectiveness of technology- enhanced simulation versus other instructional methods: a systematic review and meta-analysis. Simul Healthc 7: 308-320.

47. Ilgen JS, Sherbino J, Cook DA (2013) Technology enhanced Simulation in Emergency Medicine: A Systematic Review and Meta-Analysis. Acad Emerg Med 20(2): 117-127.

48. Sharma S, Boet S, Kitto S, Reeves S (2011) Interprofessional simulated learning: the need for 'sociological fidelity' J Interprof Care 25(2): 81-83.

49. Fitch MT (2007) Using high-fidelity emergency simulation with large groups of preclinical medical students in a basic science course. Med Teach 29(2-3): 261-263.

50. Zinan N, Puia D, Kinsley T (2015) Results of a mass casualty incident simulation in an undergraduate nursing program. J Nurs Educ Pract 5(12): 71.

51. Edwards NA, Caldicott DG, Eliseo T, Pearce A (2016) Truth hurts-hard lessons from Australia's largest mass casualty exercise with contaminated patients. Emerg Med Australas 18(2): 185-195.

52. Alinier G (2010) Developing high-fidelity health care simulation scenarios: A guide for educators and professionals. Simul Games 42(1): 9-26.

53. Meyers NM, Nulty DD (2012) How to use (five) curriculum design principles to align authentic learning environments, assessment, students' approaches to thinking and learning outcomes. Assessment Evaluation Higher Educ 34(5): 565-577. 